\title{
linc-HOXA1 is a noncoding RNA that represses Hoxa1 transcription in cis
}

\author{
Hédia Maamar, ${ }^{1}$ Moran N. Cabili, ${ }^{2,3,4}$ John Rinn, ${ }^{2,4}$ and Arjun Raj ${ }^{1,5}$ \\ ${ }^{1}$ Department of Bioengineering, University of Pennsylvania, Philadelphia, Pennsylvania 19104, USA; ${ }^{2}$ Broad Institute \\ of Massachusetts Institute of Technology and Harvard, Cambridge, Massachusetts 02142, USA; ${ }^{3}$ Department of Systems \\ Biology, Harvard Medical School, Boston, Massachusetts 02115, USA; ${ }^{4}$ Department of Stem Cell and Regenerative Biology, \\ Harvard University, Cambridge, Massachusetts 02138, USA
}

Recently, researchers have uncovered the presence of many long noncoding RNAs (IncRNAs) in embryonic stem cells and believe they are important regulators of the differentiation process. However, there are only a few examples explicitly linking lncRNA activity to transcriptional regulation. Here, we used transcript counting and spatial localization to characterize a lncRNA (dubbed linc-HOXA1) located $\sim 50 \mathrm{~kb}$ from the Hoxa gene cluster in mouse embryonic stem cells. Single-cell transcript counting revealed that linc-HOXA1 and Hoxa1 RNA are highly variable at the single-cell level and that whenever linc-HOXA1 RNA abundance was high, Hoxa1 mRNA abundance was low and vice versa. Knockdown analysis revealed that depletion of linc-HOXA1 RNA at its site of transcription increased transcription of the Hoxa1 gene cis to the chromosome and that exposure of cells to retinoic acid can disrupt this interaction. We further showed that linc-HOXA1 RNA represses Hoxa1 by recruiting the protein PURB as a transcriptional cofactor. Our results highlight the power of transcript visualization to characterize IncRNA function and also suggest that PURB can facilitate lncRNA-mediated transcriptional regulation.

[Keywords: gene regulation; noncoding RNA; single molecule]

Supplemental material is available for this article.

Received March 6, 2013; revised version accepted May 6, 2013.

With the advent of tiling microarrays and RNA sequencing, researchers have discovered that transcription occurs in many regions of the genome not previously thought to be transcriptionally active (Carninci et al. 2005; Kapranov et al. 2005; The ENCODE Project Consortium et al. 2007; Mercer et al. 2009; Cabili et al. 2011; Rinn and Chang 2012; Derrien et al. 2012). In particular, some of these regions (thought to number in the thousands) (Cabili et al. 2011; Derrien et al. 2012) encode long noncoding RNA molecules (lncRNAs) with little apparent coding potential, despite being spliced and polyadenylated much like messenger RNA (mRNA). While many lncRNAs display conservation between species (Ponting et al. 2009), suggesting that they may play some role in cellular function, the exact role of the vast majority of these molecules remains unclear, often due to technical difficulties associated with the manipulation of lncRNAs. However, associative studies show that lncRNAs appear to be involved in developmental processes (Pauli et al. 2011; Hu et al. 2012) and that they are particularly prevalent in embryonic stem cells and may be involved

\footnotetext{
${ }^{5}$ Corresponding author

E-mail arjunraj@seas.upenn.edu

Article published online ahead of print. Article and publication date are online at http://www.genesdev.org/cgi/doi/10.1101/gad.217018.113.
}

in the regulation of pluripotency (Dinger et al. 2008; Hawkins and Morris 2010; Guttman et al. 2011).

The four Hox gene clusters in mammalian genomes provide an ideal testing ground for studying the function of lncRNAs given that (1) they contain key developmental regulators with broad conservation; (2) their genetic organization is strongly linked to their expression properties, providing candidates for regulation; and (3) they contain a very large number of lncRNAs (Petruk et al. 2006; Mainguy et al. 2007; Rinn et al. 2007; Zhang et al. 2009; Wang et al. 2011). Indeed, several groups have already demonstrated that particular lncRNAs in the cluster appear to regulate some of the Hox genes in the cluster themselves (Petruk et al. 2006; Rinn et al. 2007; Zhang et al. 2009; Wang et al. 2011), part of a broader class of lncRNAs that regulate genetically proximal genes (Ørom et al. 2010; Ørom and Shiekhattar 2011; Wang et al. 2011; Lai et al. 2013). Still, the function (if any) of the majority of lncRNAs in and around the Hox clusters remains unknown.

Here, we elucidated the function of a lncRNA, dubbed linc-HOXA1, located $\sim 50 \mathrm{~kb}$ away from the Hoxa1 gene in the Hoxa gene cluster in mice through the use of single-molecule RNA imaging and single-cell analysis. While bulk assays averaging together many cells treated with retinoic acid initially suggested that linc-HOXA1 
RNA may activate Hoxa1 transcription, single-molecule transcript counting revealed that individual cells can have high abundance of linc-HOXA1 RNA or Hoxa1 mRNA but never both, suggesting instead that lincHOXA1 RNA serves to transcriptionally repress Hoxa1. We confirmed this negative regulation by knocking down linc-HOXA1 RNA at the site of its transcription, demonstrating that the regulation appears to occur in cis to the chromosome rather than through a trans mechanism. We further demonstrated that this effect is due to a particular region of the RNA that recruits the transcriptional regulator PURB to the site of transcription. We believe our results highlight the potential for single-cell analysis in uncovering the gene regulatory roles of lncRNAs.

\section{Results}

Identification and characterization of the linc-HOXA1 transcript

Previous studies have found regulatory lncRNAs flanking the Hoxa locus in mice-one on the $5^{\prime}$ end of the cluster located beyond Hoxa13 (Zhang et al. 2009; Wang et al. 2011) and one near the $3^{\prime}$ end of the cluster located between Hoxa1 and Hoxa2 (Zhang et al. 2009). However, deep sequencing results in mouse embryonic stem cells (Guttman et al. 2010) have revealed the existence of another lncRNA (linc-HOXA1) located $\sim 50 \mathrm{~kb} \mathrm{3'}$ of Hoxa1 (Fig. 1A). linc-HOXA1 is transcribed in the opposite direction $\left(5^{\prime} \rightarrow 3^{\prime}\right)$ of Hoxal, and the gene is $\sim 12 \mathrm{~kb}$ long. Cloning of the linc-HOXA1 transcripts uncovered the presence of three different isoforms (Fig. 1A), consistent with RNA sequencing studies (Guttman et al. 2010).

We then sought to establish that linc-HOXA1 encodes a noncoding RNA transcript. While the transcript did not contain any ORFs longer than 151 codons, recent studies have suggested that several lncRNAs may in fact encode short peptides (Ingolia et al. 2011). To rule out this possibility, we analyzed the linc-HOXA1 coding sequence using phyloCSF (phylogenetic codon substitution frequency) (Lin et al. 2011), a conservation-based method that estimates whether a multispecies nucleotide sequence alignment in a specific locus is more likely to represent a protein coding than a noncoding transcript (Materials and Methods). The low phyloCSF score (9.2) of linc-HOXA1 is more in line with those of other known noncoding RNAs than with those of known protein coding transcripts (Fig. 1B). To further check for coding potential in linc-HOXA1, we overexpressed each isoform in HeLa cells at levels considerably higher than GAPDH and analyzed all of the resulting small peptides via mass spectrometry (Materials and Methods; Fig. 1C; Supple-

A
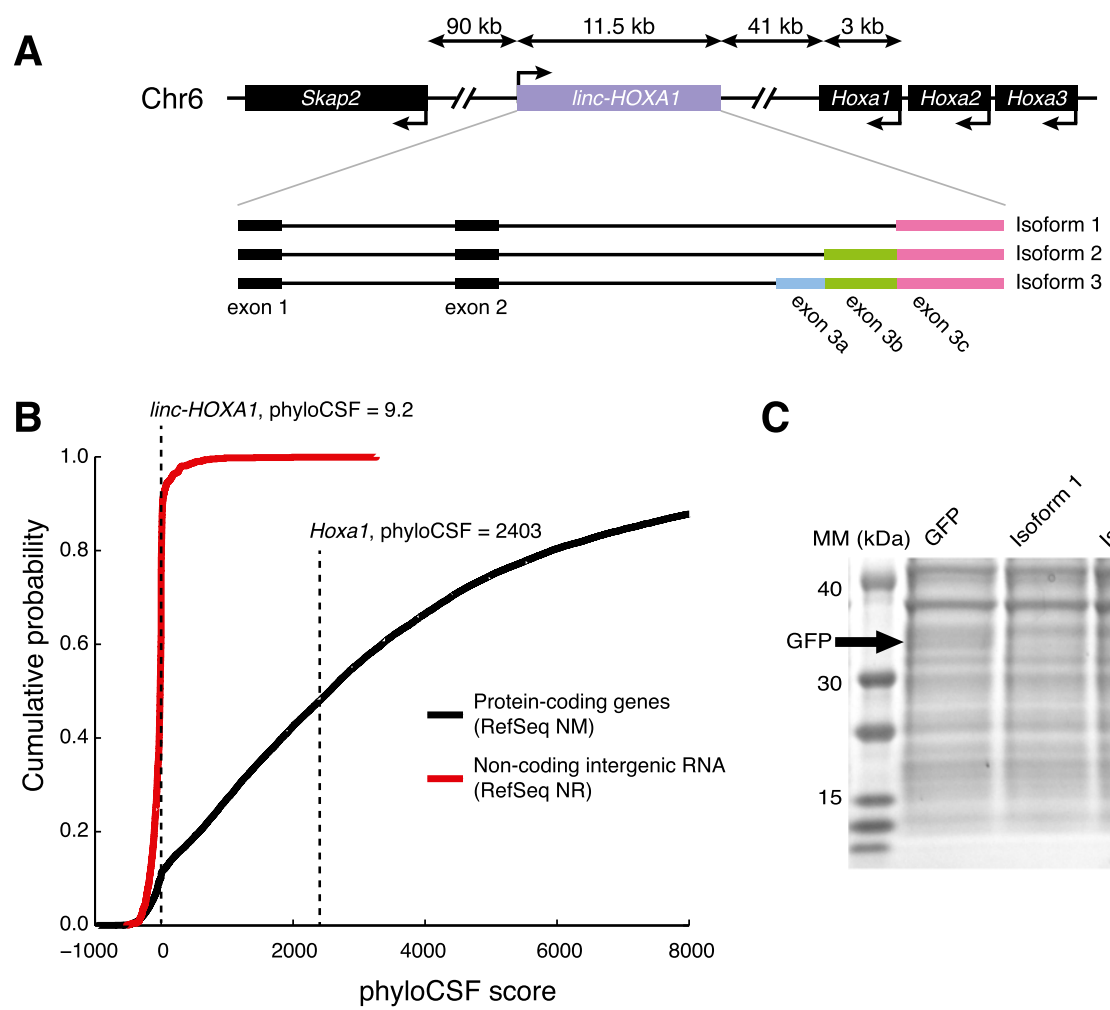

C

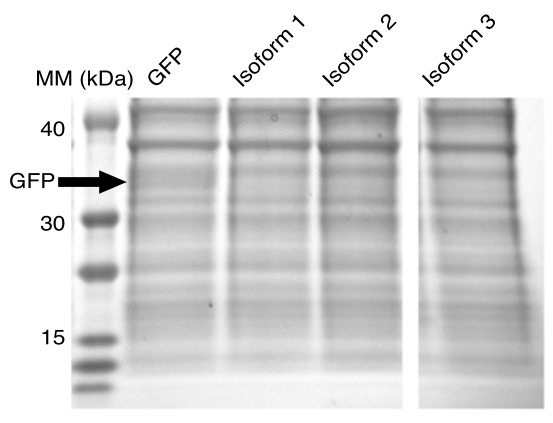

Figure 1. Identification and characterization of linc-HOXA1 as a noncoding RNA. (A) Illustration of the genomic location and transcript structure of the linc-HOXA1 gene and its three isoforms. (B) Cumulative probability distribution of coding potential as measured by phyloCSF score (Materials and Methods) for both noncoding transcripts (RefSeq NR, red) and coding transcripts (RefSeq NM, black). Dashed lines represent the coding potential of linc-HOXA1 and Hoxa1. (C) Protein gel stained with Coomassie blue upon overexpression of GFP (control) or linc-HOXA1 isoforms 1, 2, and 3 in HeLa cells. Markers at the left of the gel indicate protein size, and the arrow shows the expected size of the GFP protein. 
mental Fig. 1). We did not find any peptide matches to those encoded by short ORFs in any of the isoforms we cloned, indicating that these transcripts do not encode proteins. We also note here that the subsequent functional studies we outline below provide further evidence that linc-HOXA1 does not encode functional small peptides.

\section{Single-molecule detection of linc-HOXA1 isoforms in individual cells}

In order to detect and quantify the different isoforms of linc-HOXA1 RNA in individual cells, we generated sets of oligonucleotide probes for RNA fluorescence in situ hybridization (RNA FISH) (Raj et al. 2008; Raj and Tyagi 2010) that were specific to each isoform (Supplemental Table 1). By looking for colocalization of signal from probes targeting various parts of the different isoforms, we were able to detect and quantify all the three isoforms at the level of single molecules in individual cells (Fig. 2A). We found that isoform 1 was the dominant isoform at $\sim 41 \%$ of the total, with isoforms 2 and 3 making up the remaining $27 \%$ and $8 \%$, respectively (Fig. 2B). We also observed other partial isoforms, but the partial isoforms were only $\sim 24 \%$ of the total transcripts detected and may represent partial isoforms undergoing degradation (Fig. 2B). At the single-cell level, we found that each of these isoforms correlated very strongly with each other (Fig. 2C); hence, for simplicity, we used a set of probes optimized to target all isoforms for the rest of the analysis in this study.

\section{Differentiation dynamics and single-cell analysis of linc-HOXA1}

The close proximity of linc-HOXA1 to the Hoxa gene cluster along with the fact that the Hox gene expression is related to their genetic organization suggested to us that the transcription of linc-HOXA1 may be tied to that of the nearby Hox genes and may in fact play some regulatory role therein (Fig. 3A). We first examined this possi-
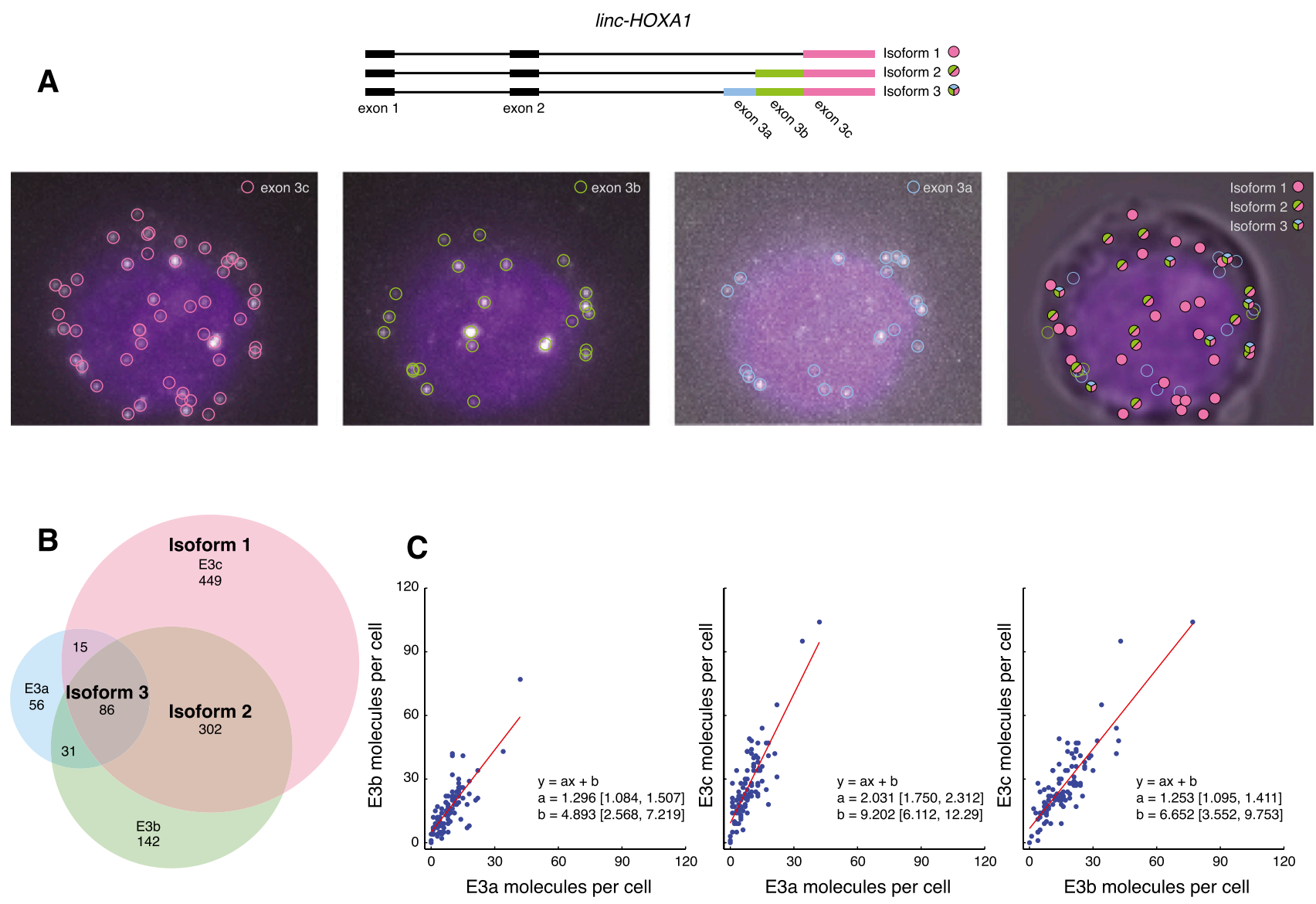

Figure 2. Detection of individual RNA isoforms of linc-HOXA1 in single cells. $(A)$ Raw micrographs of a single cell containing all three isoforms. (Three left panels) We designed probes specifically targeting exons $3 \mathrm{c}, 3 \mathrm{~b}$, and $3 \mathrm{a}$, each of which revealed single spots corresponding to individual molecules. The circles represent the computationally identified spot locations (determined in three dimensions). (Right panel) We then looked for colocalization of the spots and used that to determine which combinations of spots represented particular isoforms. The unfilled circles in the right panel represent spots that we were unable to classify as being isoform 1 , 2, or 3. (B) Venn diagram showing the relative abundances of the various combinations of exons $3 \mathrm{a}, 3 \mathrm{~b}$, and $3 \mathrm{c}$ that we detected through colocalization analysis. Labels indicate the combinations that correspond to the three isoforms identified by sequencing and cloning. $(C)$ Pairwise scatter plots showing the numbers of exons $3 \mathrm{a}, 3 \mathrm{~b}$, and $3 \mathrm{c}$ versus those same exons in individual cells. Lines represent a least-squares fit with the indicated parameters (including $95 \%$ confidence intervals). 
A

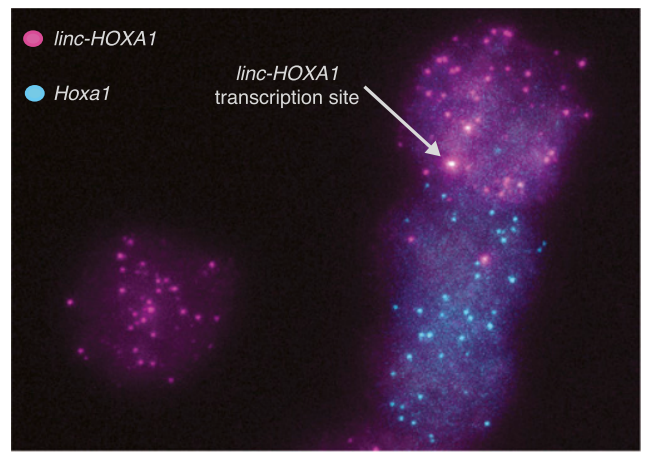

B

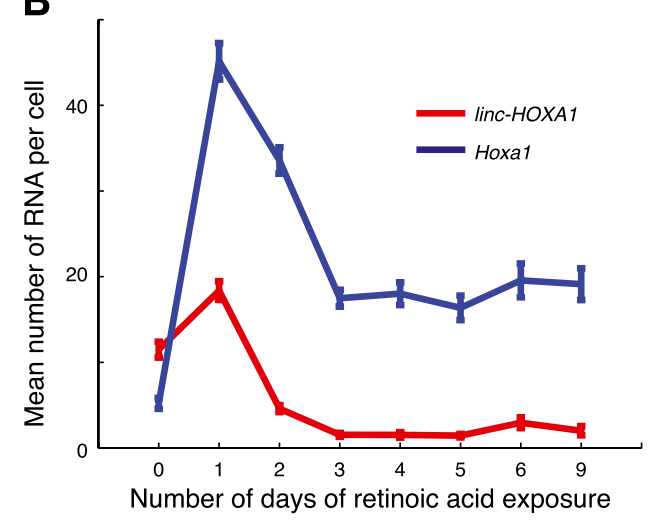

C
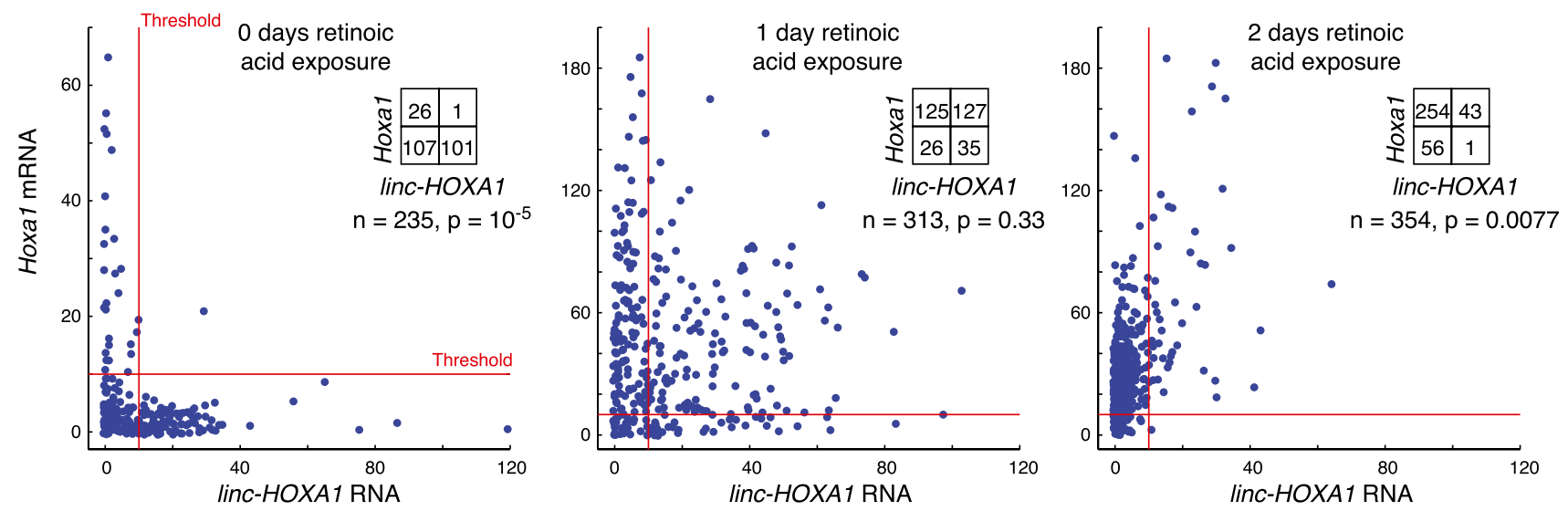

Figure 3. linc-HOXA1 and Hoxa1 anti-correlate at the single-cell level. (A) Micrographs of three representative mouse embryonic stem cells expressing linc-HOXA1 (red) and Hoxa1 (blue). The arrow points to the location of an active transcription site. $(B)$ Average numbers of linc-HOXA1 (red) and Hoxa1 (blue) RNA molecules per cell in embryonic stem cells exposed to retinoic acid for increasing durations as measured by single-molecule RNA FISH. Error bars represent standard error. The numbers of cells in each condition are $235,313,354,351,280,204,165$, and 189 (0-6 and 9 d retinoic acid, respectively). (C) Single-cell scatter plots of linc-HOXA1 and Hoxa1 RNA abundance at 0,1 , and $2 \mathrm{~d}$ of exposure to retinoic acid. The red lines represent thresholds that we chose for linc-HOXA1 and Hoxa1 RNA levels, set at 10 RNA molecules for each RNA species. The inset tables show the number of cells in the four quadrants delineated by the thresholds. We computed the $P$-value for the distribution of cells in the quadrants via the $\chi^{2}$ test.

bility through the addition of retinoic acid to our embryonic stem cells, which is an agent known to cause embryonic stem cells to differentiate toward a neural lineage with concomitant activation of Hoxa genes (Dupé et al. 1997). We found that exposing the cells to retinoic acid over the course of several days caused a coordinated pulse of expression of linc-HOXA1, Hoxa1 (Fig. 3B), and Hoxa2 (Supplemental Fig. 2A), peaking at $1 \mathrm{~d}$ of exposure. This population-level analysis initially suggested that lincHOXA1 and Hoxa1 might be coherently regulated by either each other or a common upstream factor in the retinoic acid pathway.

We then examined the expression of linc-HOXA1 and Hoxa1 RNA in individual cells, reasoning that single-cell correlations or anti-correlations in expression may reveal more information about potential regulatory interactions. We first looked at stem cells that had not been treated with retinoic acid. We found that both lincHOXA1 and Hoxa1 showed large cell-to-cell variability in transcript abundance. Surprisingly, we found that this variability anti-correlated in the sense that cells with a high abundance of linc-HOXA1 RNA had low numbers of Hoxa 1 mRNA and vice versa; i.e., it was very rare to find individual cells that simultaneously had high levels of linc-HOXA1 and Hoxa1 RNA (Fig. 3C). (We also note that the nearby gene Skap2 did not correlate with lincHOXA1 [Supplemental Fig. 2B], showing that correlations and anti-correlations are not generic features of transcription of this gene. In addition, Oct4 did not correlate with Hoxa1, showing that variability in Hoxa1 was not an artifact of partially differentiating cells [Supplemental Fig. 2C].) This anti-correlation disappeared, however, upon a 1-d exposure to retinoic acid (Fig. 3C), even though the relative abundance of various isoforms were similar (albeit with a modest increase in isoform 3) (Supplemental Fig. 3). Together, these findings demonstrate that while linc-HOXA1 and Hoxa1 appear to correlate in bulk population measurements, our singlecell measurements raised the possibility that lincHOXA1 RNA may actually negatively regulate Hoxa1 
transcription or vice versa and that the addition of retinoic acid overrides this negative regulation. Moreover, our single-cell analysis reveals that any putative regulation appears to behave in a sharp threshold-like manner rather than a graded response in that expression of, say, Hoxa1 drops dramatically once linc-HOXA1 reaches a particular level (in this case, we chose 10 RNA molecules as a threshold that captures this effect).

\section{Knockdown of linc-HOXA1 RNA reveals repression of Hoxal}

In order to determine whether these correlations were manifestations of a true regulatory interaction, we used two different methods to knock down linc-HOXA1 tran- script levels and analyzed the results using RNA FISH (Fig. $4 \mathrm{~A}$, top left). The first method used modified antisense oligonucleotides that bind to the RNA and prompt RNA degradation via RNase $\mathrm{H}$ activity (Liang et al. 2011). The second method used conventional siRNAs via activation of the RNAi pathway. Both methods resulted in similar decreases in overall linc-HOXA1 RNA levels $(65 \%, P=2 \times$ $10^{-7} ; 52 \%, P=4 \times 10^{-4}$, respectively). Consistent with linc-HOXA1 RNA repressing the transcription of Hoxa1, we found that knockdown via the antisense oligonucleotides resulted in an increase in Hoxa1 mRNA abundance by an average of $50 \%\left(P=2 \times 10^{-4}\right)$ (Fig. 4A). However, we found that knockdown via siRNA did not result in any change in Hoxa1 mRNA abundance.

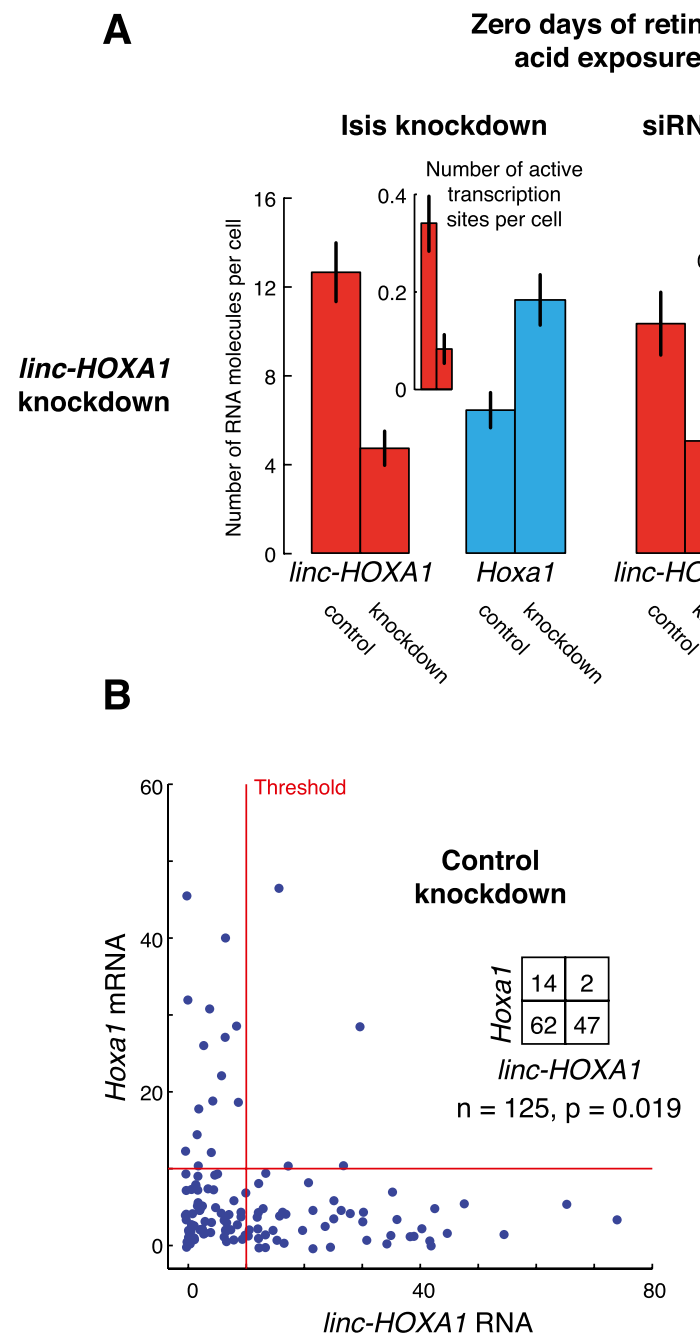

\section{ero days of retinoic}

siRNA knockdown

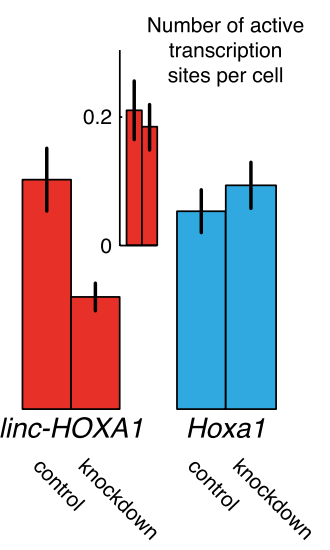

\section{One day of retinoic acid exposure}

Isis knockdown

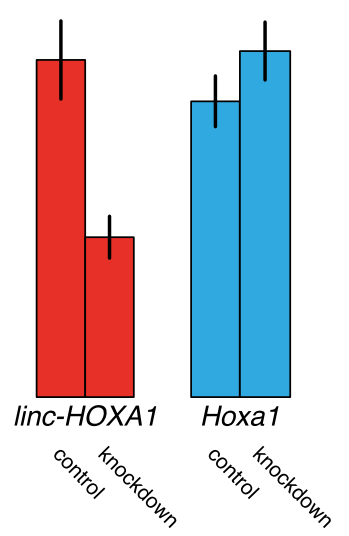

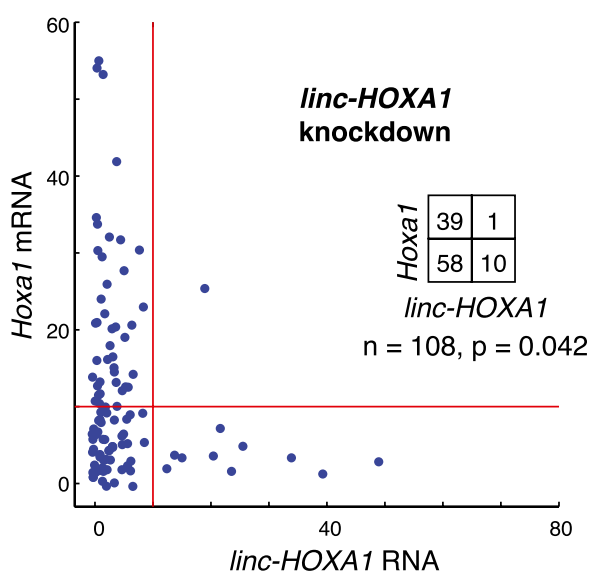

Figure 4. Knockdown of linc-HOXA1 increases Hoxa1 levels. (A) Bar graphs showing changes in average number of linc-HOXA1 and Hoxa1 RNA molecules per cell upon treatment with siRNA or Isis antisense oligonucleotides targeting either linc-HOXA1 (top row) or Hoxa1 (bottom row). In all bar graph pairs, the control condition (targeting with a nonspecific siRNA or Isis antisense oligonucleotides) is on the left. The inset bar graph shows the average number of active transcription sites in cells treated with control versus lincHOXA1 knockdown. All numbers represent counts obtained by single-molecule RNA FISH; all error bars represent standard error of the mean. (B) Single-cell scatters showing linc-HOXA1 versus Hoxa1 transcript levels upon treatment of cells with control (nonspecific) antisense oligonucleotides or antisense oligonucleotides targeting linc-HOXA1. The red lines represent the thresholds of 10 RNA molecules for each RNA species and are the same as those in Figure 3 . The inset tables show the number of cells in the four quadrants delineated by the thresholds. We computed the $P$-value for the distribution of cells in the quadrants via the $\chi^{2}$ test. 
To find the source of this discrepancy, we analyzed the knockdown of linc-HOXA1 RNA at the subcellular level. In untreated cells, we found linc-HOXA1 in both the nuclear and cytoplasmic compartments. The nuclear RNA appeared primarily as bright foci marking the site of transcription (Fig. 3A); these foci represent a pileup of nascent transcripts at the gene locus itself, as verified by colocalization of these foci with probes targeting the introns of linc-HOXA1 (Supplemental Fig. 4; Fremeau et al. 1986; Xing et al. 1993; Levesque and Raj 2013). Most of the rest of the RNA were in the cytoplasm, as verified by three-dimensional analysis of spot locations (data not shown), although it was difficult to make this assessment rigorously due to the thin layer of cytoplasm in this cell type. We thus checked whether the knockdown was effectively knocking down RNA at the site of lincHOXA1 transcription, given that any potential cis regulatory effects of linc-HOXA1 (meaning activity of lincHOXA1 on genes located near its site of transcription) would occur at this physical location. We found that the number of sites of active transcription of linc-HOXA1 per cell decreased markedly upon treatment with antisense oligonucleotides but were relatively invariant to targeting via siRNA (Fig. 4A, inset; see Supplemental Fig. 5 for representative images). These results indicate that repression of Hoxa1 by linc-HOXA1 RNA depends primarily on the presence of linc-HOXA1 RNA molecules at the site of transcription rather than the overall cellular abundance of linc-HOXA1 RNA, strongly suggesting that linc-HOXA1 regulates Hoxa1 through a mechanism mediated by the genetic proximity of these two genes. We note, however, that antisense oligonucleotide knockdown did not affect Hoxa2 expression $(1.13 \pm 0.19$ mRNA per cell in the control condition to $1.20 \pm 0.16$ mRNA per cell in the knockdown).

To examine the results of our knockdown experiment at the single-cell level, we grouped our cells into three populations: those with high levels of linc-HOXA1 (and low levels of Hoxa1 mRNA), those with high levels of Hoxa1 (and low levels of linc-HOXA1), and those with low levels of both linc-HOXA1 and Hoxa1 (Fig. 4B). We found that the apparent effect of the knockdown with antisense oligonucleotides was to shift cells from the high linc-HOXA1/low Hoxa1 group to the high Hoxa1/low linc-HOXA1 group, with few if any cells moving into the low linc-HOXA1/low Hoxa1 group. This result suggests that the fold increase in Hoxa1 mRNA levels in those cells for which linc-HOXA1 levels decreased was considerably higher than the population averages would indicate. In this case, single-cell analysis reveals that both cellular heterogeneity and the presence of a sharp threshold for repression serve to diminish the amplitude of the effects of linc-HOXA1 RNA knockdown at the population level.

Our correlation results also showed that the correlation between linc-HOXA1 and Hoxa1 mRNA levels disappeared upon addition of retinoic acid. We tested whether these correlations were a sign of a change in the functional interaction of these genes by knocking down linc$H O X A 1$ after $1 \mathrm{~d}$ of retinoic acid exposure. We found that knocking down linc-HOXA1 at this point no longer affected Hoxa1 levels, showing that activation by retinoic acid overrides the repressive function of linc-HOXA1 (Fig. 4A). Also, to verify that the anti-correlation between linc-HOXA1 and Hoxa1 was not due to the transcription factor activity of HOXA1, we also knocked down Hoxa1 mRNA both with and without addition of retinoic acid, finding that the knockdown had no effect on linc-HOXA1 RNA abundance (Supplemental Fig. 6).

\section{Overexpression of linc-HOXA1 RNA does not change} Hoxal levels

Our knockdown experiments demonstrate that lincHOXA1 RNA negatively affects the transcription of Hoxa1, and our transcription site analysis strongly suggests that linc-HOXA1 activity takes place in cis-meaning locally, near its site of transcription. In contrast, a trans mechanism of action would consist of linc-HOXA1 RNA moving within the nucleus to the Hoxa1 gene regardless of where linc-HOXA1 was originally transcribed. To confirm the cis activity and eliminate the possibility of trans activity, we transiently overexpressed each isoform of linc-HOXA1 in embryonic stem cells to look for changes in Hoxa1 transcription. Despite a ninefold or greater overexpression of the three linc-HOXA1 isoforms, we did not observe any changes in Hoxa1 mRNA abundance (Fig. 5A). At the single-cell level, the anti-correlation between linc-HOXA1 and Hoxa1 disappeared (Fig. 5B), directly revealing that cells with high levels of Hoxa1 RNA (and low initial levels of linc-HOXA1) can maintain those high levels of Hoxa1 RNA even upon addition of exogenous linc-HOXA1 RNA to those same cells. Adding linc-HOXA1 to cells that initially had very little lincHOXA1 precludes the possibility that the lack of change in Hoxa1 mRNA levels is due to our merely increasing (to nonphysiologically relevant levels) linc-HOXA1 RNA numbers in cells that already had high amounts of lincHOXA1 to begin with.

Combining these results with our linc-HOXA1 knockdown results, we conclude that the regulation of Hoxa1 by linc-HOXA1 occurs largely due to the local activity of linc-HOXA1 near its site of transcription. We also note that these results provide further evidence that the lincHOXA1 transcripts do not encode a protein (including any short peptides) that mediates its transcriptional effects: In such a scenario, overexpression would result in an increase in proteins and thus would have resulted in a trans repression of the Hoxa1 mRNA production.

linc-HOXA1 exerts its repressive effects through interaction with PURB

There are several examples of lncRNAs that alter gene expression via the recruitment of proteins involved in transcriptional regulation (Rinn et al. 2007; Lee 2012; Hawkins and Morris 2010; Huarte et al. 2010). To check what proteins linc-HOXA1 RNA may be associated with, we biotinylated in vitro synthesized RNA corresponding to RNA containing a variety of different exons from lincHOXA1 (Fig. 6A) and used them to pull out proteins 
A
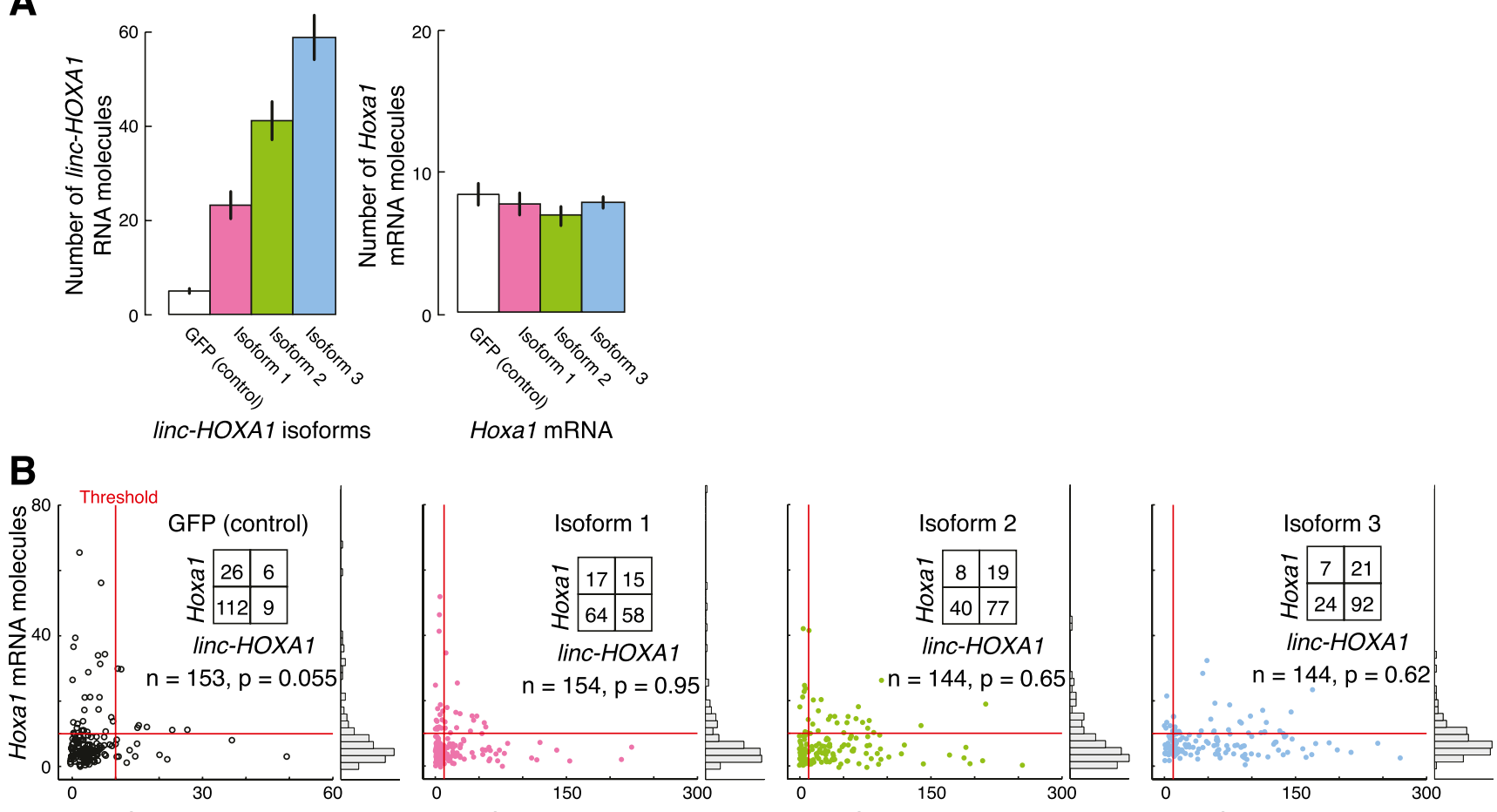

linc-HOXA1 RNA molecules

linc-HOXA1 RNA molecules

linc-HOXA1 RNA molecules

linc-HOXA1 RNA molecules

Figure 5. Overexpression of linc-HOXA1 isoforms does not alter Hoxa1 abundance. (A) Bar plots showing the number of the various linc-HOXA1 RNA isoforms overexpressed in embryonic stem cells (and a vector containing GFP as a control) (left) and the resultant number on Hoxa1 transcripts (right). Overexpression is likely underestimated due to high levels of expression, resulting in some spot undercounting. All error bars represent standard error of the mean. (B) Single-cell scatter plots showing linc-HOXA1 versus Hoxa1 transcript levels upon overexpression of GFP or each of the three linc-HOXA1 isoforms. The red lines represent the thresholds of 10 RNA molecules for each RNA species and are the same as those in Figures 3 and 4 . The inset tables show the number of cells in the four quadrants delineated by the thresholds. We computed the $P$-value for the distribution of cells in the quadrants via the $\chi^{2}$ test.

from embryonic stem cell lysate (Fig. 6B). We separated these proteins by electrophoresis and looked for bands with differential intensity between the antisense RNA controls and the various synthetic RNAs used. We found a prominent band (Fig. 6B) and used mass spectrometry to identify the proteins that bound specifically to various isoforms of linc-HOXA1. Of particular interest was the protein encoded by Purb, a known modulator of transcription (Ramsey and Kelm 2009); indeed, experiments show that a related protein, PURA, which often binds together with PURB, can mediate transcriptional regulation via lncRNA (Hawkins and Morris 2010). PURB binds to purine-rich tracts of single-stranded nucleic acids (Bergemann and Johnson 1992; Gallia et al. 1999), and mass spectrometry revealed that PURB was bound only to RNA that contained the long stretch of guanines and adenosines in the middle of exon $3 \mathrm{~b}$ (Fig. 6B).

In order to verify whether this interaction occurred inside of embryonic stem cells, we wanted to use an antibody against PURB to pull down all RNA associated with PURB. Lacking an effective antibody that targeted PURB directly, we instead overexpressed a version of Purb in which we incorporated a Myc Flag tag into the protein coding sequence. We then pulled down the RNA and used RT-PCR to check for the presence of lincHOXA1 RNA, finding that linc-HOXA1 RNA was indeed bound to PURB in vivo (Fig. 6C). Together, these results strongly suggest that linc-HOXA1 RNA interacts with PURB in mouse embryonic stem cells.

To check whether the interaction of linc-HOXA1 and PURB is important for linc-HOXA1 to repress the transcription of Hoxa1, we knocked down Purb mRNA and looked for changes in the relationship between lincHOXA1 and Hoxa1. We found that Hoxa1 mRNA levels increased upon Purb mRNA knockdown (Fig. 6D) and that the anti-correlation between linc-HOXA1 RNA and Hoxa1 mRNA at the single-cell level disappeared (Fig. $6 \mathrm{E})$, showing that PURB is critical in mediating lincHOXA1 RNA's repressive effects.

\section{Discussion}

Here, we showed that the lncRNA linc-HOXA1 acts to repress the transcription of Hoxa1 and that this repression occurs in cis to the chromosome. We discovered this regulation through the use of single-cell multiplex transcript counting, which enabled us to see effects that otherwise may be difficult to observe using bulk measurements. 

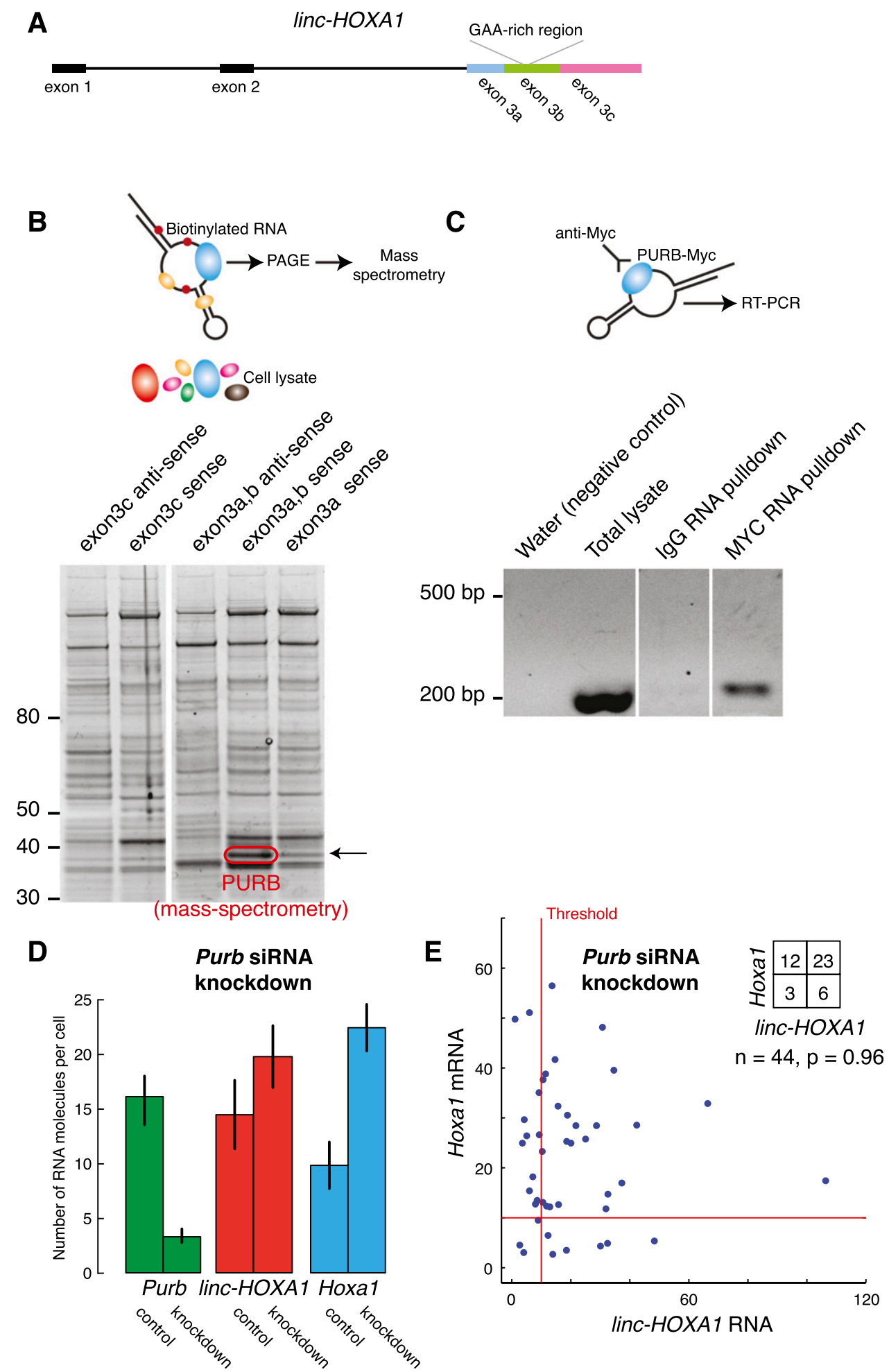

Figure 6. PURB binds to linc-HOXA1 in vitro and in vivo and mediates repression of Hoxa1 transcription. $(A)$ Illustration of lincHOXA1 gene structure showing the location of the GAA purine-rich region. (B) Protein products visualized by gel electrophoresis that we pulled down using different biotinylated linc-HOXA1 deletion and antisense transcripts (lanes are from the same gel, reordered for clarity). The arrow points to the length of bands containing PURB, and the red circle indicates the band that contained PURB, as determined by mass spectrometry. $(C)$ We transfected Myc-tagged Purb into mouse embryonic stem cells, immunoprecipitated them, performed RT-PCR, and ran the products on an agarose gel to detect the presence of the linc-HOXA1 transcript. The "water" lane (shown at left) served as a negative control for the PCR reaction, "total lysate" omits the immunoprecipitation step, "IgG" used an IgG antibody for the immunoprecipitation, and "MYC" used a MYC antibody to pull down Myc-tagged PURB. (D) Purb siRNA knockdown and the effects on linc-HOXA1 and Hoxa1 transcript levels. Error bars report the standard error of the mean. (E) Scatter plots showing number of linc-HOXA1 and Hoxa1 transcript levels in single cells in Purb knockdown conditions. The inset table shows the number of cells in the four quadrants delineated by the thresholds. We computed the $P$-value for the distribution of cells in the quadrants via the $\chi^{2}$ test. 
We found that the repression of Hoxa1 by linc-HOXA1 RNA disappeared upon the addition of retinoic acid, showing that linc-HOXA1 RNA exerts its regulatory influence on Hoxa1 only in the absence of retinoic acid. These results suggest that the mechanism of action of linc-HOXA1 RNA is presumably easy to override by the binding of the retinoic acid receptor to its cognate binding sites in the Hoxa1 promoter (Dupé et al. 1997). Also, lincHOXA1 is relatively distal from the hoxa1 gene locus $(\sim 50 \mathrm{~kb})$. One possibility is that in the absence of retinoic acid, the Hoxa cluster adopts a conformation in which linc-HOXA1 is physically proximal to the Hoxa1 locus, but upon addition of retinoic acid, the binding of the retinoic acid receptor to its binding site (and subsequent activation) induces a conformational change that pulls linc-HOXA1 away from the Hoxa1 locus, thereby making that regulatory interaction impossible. Indeed, several other results have suggested a relationship between cis regulation by lncRNAs and chromosome structure (Zhang et al. 2009; Ørom and Shiekhattar 2011; Wang et al. 2011; Lee 2012; Tan-Wong et al. 2012; Lai et al. 2013), and we further note the excellent work of Petruk et al. (2006) in which the investigators demonstrate regulation in Drosophila Hox genes by a lncRNA over a distance scale similar to that which we observed here. Such an interpretation is certainly consistent with our results showing that upon addition of retinoic acid, the correlation between linc-HOXA1 and Hoxa1 disappears, and linc-HOXA1 RNA knockdown produces no effect. We further note that others have shown that the lncRNA HOTAIR-M1, located between Hoxa1 and Hoxa2, serves to activate Hoxa1 only upon addition of retinoic acid (Zhang et al. 2009). Taken together, these results point to regulation of Hoxa1 by a pair of lncRNAs-one that represses it before retinoic acid induction, and one that activates it upon induction.

Another striking feature of linc-HOXA1 repression of Hoxa1 was that it appeared to involve a very sharp threshold, meaning that linc-HOXA1 had to be below $\sim 10$ molecules per cell in order for us to observe significant Hoxa1 transcript levels. It is possible that the manner by which lncRNAs regulate gene expression lends itself to the generation of such thresholds. On a technical note, the existence of sharp thresholds can often obscure the effects of RNA knockdown. For instance, here we knocked down linc-HOXA1, resulting in an increase in Hoxa1 mRNA abundance, but the effects on the overall population are seemingly moderate due to the fact that while many (although not all) cells have some partial reduction in linc-HOXA1 levels, only a few cells are reduced to subthreshold levels, and thus those are the only ones with an increase in Hoxa1 mRNA abundance. It is possible that such thresholds may obscure the potential regulatory roles of many lncRNAs as measured by conventional assays. Such thresholds may play an important role in developmental switches (Maamar et al. 2007; Choi et al. 2008; Raj et al. 2010).

Interestingly, we also observed that in cells with high levels of linc-HOXA1, knockdown of linc-HOXA1 resulted in those same cells then having relatively high levels of Hoxa1, rather than a mixture of high and low Hoxa1 transcript abundances, as in the population overall. These results suggest that the cells fluctuate between two general states: one in which the linc-HOXA1/Hoxa1 genomic region is transcriptionally inert, and one in which that region is transcriptionally active. For the cells that are in the transcriptionally active state, they have a choice to transcript either linc-HOXA1 or Hoxa 1 but not both. In that case, a knockdown would result in those cells with high linc-HOXA1 expression becoming cells with high Hoxa1 expression, consistent with our data. It is possible that the transitions between the region being transcriptionally active and transcriptionally inert reflect the transcriptional changes associated with widespread phenomenon of transcriptional "bursts," which are short but intense periods of transcription interspersed between periods of transcriptional silence (Golding et al. 2005; Chubb et al. 2006; Raj et al. 2006; Ingolia et al. 2011; Suter et al. 2011). In that case, it may be that at the onset of a transcriptional burst in the region, either linc-HOXA1 or Hoxa1 may begin transcribing, but if linc-HOXA1 starts transcribing first, it will repress Hoxa1 and prevent it from transcribing during that burst. It is possible that this population that is transcriptionally competent at the $3^{\prime}$ end of the Hoxa gene cluster represents embryonic stem cells that are transiently primed for differentiation, and that lincHOXA1 provides some regulation of the differentiation process.

Together, our findings provide strong evidence that lincHOXA1 represses Hoxa1 in cis through a sharp threshold. How might such a threshold arise? One possibility is that as soon as nascent linc-HOXA1 RNA is transcribed, PURB binds to it and then represses the transcription of Hoxa1 mRNA. In such a scenario, the production of even just a few transcripts during a burst of linc-HOXA1 transcription would be enough to repress Hoxa1, thereby resulting in the sharp repression threshold that we observed. Such thresholds may serve important roles in digitizing transcriptional output, and if such mechanisms end up being ubiquitous features of lncRNA function, it may be that lncRNAs are a class of molecule particularly well suited for producing such responses. Such responses may also depend on the nature of the protein cofactor involved in the transcriptional control, and so it may be worth searching for other lncRNAs that may act similarly through interactions with PURB (or its close relative, PURA) (Hawkins and Morris 2010).

More generally, we believe that our approach of looking for regulatory interactions by analyzing single-cell correlations in transcript abundance may prove generally useful. In particular, we think such tools may be of particular utility in the analysis of lncRNAs, which are often hard to knock down effectively due to nuclear localization and for which overexpression may not produce effects if the lncRNA acts in cis. We anticipate that the use of correlations in combination with genome-wide techniques will provide many new insights into the functional roles of lncRNAs. 


\section{Materials and methods}

\section{Cell culture}

We used the embryonic mouse cell line V6.5 (ThermoFisher Scientific), which we grew and maintained according to manufacturer's instructions. Briefly, cells were cultured at $37^{\circ} \mathrm{C}$ in a $5 \%(\mathrm{v} / \mathrm{v}) \mathrm{CO}_{2}$ incubator in KnockOut D-MEM medium (Invitrogen) supplemented with 10\% FBS (GlobalStem), 2 mM L-glutamine, $1 \%(\mathrm{v} / \mathrm{v})$ nonessential amino acids (Invitrogen), $10^{3} \mathrm{U} / \mathrm{mL}$ LIF (Millipore), and $1 \mathrm{mM}$ 2-mercaptoethanol. We coated the dishes with gelatin $(0.2 \%[\mathrm{v} / \mathrm{v}])$ and grew the cells on top of a layer of feeder cells (C57BL/6 mouse embryonic fibroblasts, GlobalStem). Cells were passaged as needed, and the growth medium was changed every day. To induce differentiation, cells were grown with no feeder layer in culture medium devoid of LIF supplemented with $5 \mu \mathrm{M}$ retinoic acid. HeLa cells (gift from the laboratory of Phillip Sharp, Massachusetts Institute of Technology) were grown in Dulbecco's modified Eagle's medium (DMEM) with Glutamax (Life Technologies) supplemented with penicillin/streptomycin and $10 \%$ fetal bovine serum.

\section{RNA FISH}

For RNA FISH, embryonic stem cells were recovered from the culture dish by trypsin EDTA $(0.25 \%)$. Feeder cells were removed from this mixture by incubating all of the cells for $45 \mathrm{~min}$ on gelatin-coated plates, in which time the feeder cells adhered to the bottom, thereby separating them from the embryonic stem cells. Nonadherent undifferentiated cells or retinoic aciddifferentiated cells were washed with $1 \times$ PBS and resuspended in $1 \times$ PBS containing $1 \%$ BSA and $2 \mathrm{mM}$ EDTA, to which we added formaldehyde for a final concentration of $4 \%$ for fixation. After 10 min of fixation, cells were washed twice with $1 \times$ PBS and stored in $70 \%$ ethanol at $4^{\circ} \mathrm{C}$ until we proceeded with RNA FISH.

RNA FISH staining followed Raj et al. (2008) with slight modifications. Fixed cells in suspension were washed with $1 \times$ PBS with $0.1 \%$ Triton and were allowed to adhere to poly-Llysine-coated coverslip chambers before hybridization. Samples were imaged on a standard inverted epifluorescence microscope (Nikon Ti-E) using a 100× 1.43 NA oil immersion objective and a Princeton Instruments Pixis 1024BR cooled CCD camera. Thirty-five $Z$ sections with a $0.35-\mu \mathrm{m}$ spacing were taken for each field of view. Image analysis was performed using custom scripts in Matlab. RNA spot counting was performed as previously described (Raj et al. 2008), and colocalization of mRNA spots from different channels was performed as described by Levesque and Raj (2013). The oligonucleotide sequences that we used in our RNA FISH probes are in Supplemental Table 1, and the binding locations for lincHOXA1 exons $3 \mathrm{a}, 3 \mathrm{~b}$, and $3 \mathrm{c}$; the entire linc-HOXA1 transcript; and the linc-HOXA1 intron are provided in Supplemental File 1. We believe our probes provide specificity based on previous experiments from our laboratory and others (Vargas et al. 2005; Raj et al. 2008) and the fact that we observed colocalization of differently labeled probes targeting different areas of the same transcript.

\section{RNA knockdown experiments}

The DNA oligonucleotides used to knock down linc-HOXA1 were manufactured by Isis Pharmaceuticals and are thought to target nuclear as well as cytoplasmic RNA for degradation through the activity of RNase $\mathrm{H}$. The following oligonucleotides were used (5' to $3^{\prime}$ ): linc-HOXA1, TGCTGCAAGGCTTTACCCGA (Isis, no. 474983) and CCCACTGAAGATAGATCGGA (Isis, no. 474990); and control (no specific target), CCTTCCCTGAAGGTTCCTCC (Isis, no. 141923).

Transfections using a 40-nM pool of oligonucleotides were carried out in 12-well plates with using Lipofectamine as a transfection reagent.

We also targeted both linc-HOXA1 and Hoxal via conventional siRNAs (Ambion) using pools of oligonucleotides at $50 \mathrm{nM}$ and Lipofectamine 2000 as a transfection reagent.

siRNAs targeting linc-HOXA1 with the same sequences as Isis oligos and the siRNAs targeting Hoxa1 in the embryonic stem cells had the following sequences $\left(5^{\prime}-3^{\prime}\right)$ : GCAGCGAU GAGAAAACGGATT and GACCUUUGACUGGAUGAAATT.

Additionally, three 27-mer siRNA duplexes targeting Purb were purchased from OriGene (catalog no. SR410793) and used at a final concentration of $10 \mathrm{nM}$ with Lipofectamine 2000 (Invitrogen) as a transfection reagent.

In all cases, cells were harvested after $24 \mathrm{~h}$ of transfection, fixed as described above, and then analyzed by RNA FISH.

\section{Cloning}

We cloned the linc-HOXA1 transcripts by amplifying cDNA from RNA isolated from undifferentiated embryonic stem cells. Primers to clone the linc-HOXA1 were designed based on the sequence deduced from RNA sequencing data and bioinformatic analysis (Guttman et al. 2010). Using the primers in Supplemental Table 2, we obtained the three different isoforms of lincHOXA1 described in the text. We cloned both sense and antisense constructs into a TOPO vector for the generation of in vitro RNA from the $\mathrm{T} 7$ promoter.

We also cloned the three isoforms and GFP into pcDNA\#.1(-) plasmid (Invitrogen) for overexpression via the CMV promoter by transfection into both the HeLa and mouse embryonic stem cells. The GFP sequence was amplified by PCR using the primers GFPFor and GFPRev (Supplemental Table 2) from pGEMT-GFP (Clontech).

\section{Coding potential via phyloCSF}

We used phyloCSF (Lin et al. 2011) to estimate the degree of evolutionary pressure on sequence substitutions acting to preserve an ORF in each of the linc-HOXA1 isoforms that we cloned as well as all coding transcripts and intergenic noncoding transcripts annotated in RefSeq (Pruitt et al. 2003). Briefly, phyloCSF determines whether a multispecies nucleotide sequence alignment in a specific locus is more likely to represent a protein coding than a noncoding transcript. It does so by applying a probabilistic model that examines the overrepresentation of evolutionary signatures characteristic of alignments of conserved coding regions, such as the high frequencies of synonymous codon substitutions and conservative amino acid substitutions.

\section{Coding potential from protein overexpression}

The pcDNA vectors expressing the three isoforms and GFP were transfected into HeLa cells using $20 \mu \mathrm{g}$ of plasmid and Lipofectamine 2000 (Invitrogen) as a transfection reagent. Cells were released from the culture dish by trypsin EDTA $(0.05 \%)$, washed with cold $1 \times$ PBS, and then lysed using CellLytic M (Sigma). Lysate was cleared of cell debris by centrifugation at 
$13,000 \mathrm{rpm}$ for $20 \mathrm{~min}$. Protein concentration in the lysate was determined using the BCA protein assay kit (Pierce) with BSA as a standard. Proteins from each cell lysate were separated by a $10 \%-20 \%$ gradient Tricine SDS-polyacrylamide gel (Invitrogen) in SDS Tricine buffer. The proteins on the gel were visualized using the Simply Blue safe stain (Invitrogen). The protein content of the bottom $1 \mathrm{~cm}$ of the gel (corresponding to proteins $<18 \mathrm{kDa}$ ) in each sample was analyzed by targeted mass spectrometry. The samples were digested with trypsin and analyzed with nanoliquid chromatography/tandem mass spectrometry (nanoLC/ MS/MS) at the University of Pennsylvania Proteomics Core. The data were analyzed with Sequest and Scaffold software packages. A database of all possible peptide masses encoded by the linc-HOXA1 isoforms (Supplemental Table 3) was included along with the UniProt Human database in the analysis of the raw data.

\section{RNA pull-downs}

Biotin-labeled RNA of the three isoforms of linc-HOXA1, along with deletions of these isoforms and antisense versions, were prepared using the Biotin RNA labeling mix (Roche) and T7 RNA polymerase (Roche). Biotinylated RNAs were treated with RNase-free DNase I (Roche) and purified on prepacked spin columns with Bio-Gel P-30 in $1 \times$ saline sodium citrate (Bio-Rad).

Mouse embryonic stem cell lysate was prepared from $5 \times 10^{7}$ cells that were collected by trypsinization and washed with cold $1 \times$ PBS. Cell were suspended in $4 \mathrm{~mL}$ of RNA immunoprecipitation (RIP) buffer (150 mM KCl, $25 \mathrm{mM}$ Tris at $\mathrm{pH} 7.4,5 \mathrm{mM}$ EDTA, $0.5 \mathrm{mM}$ DTT, $0.5 \%$ NP40, $1 \times$ protease inhibitor cocktail [Sigma]) (Rinn et al. 2007). Cells were incubated in the buffer for $30 \mathrm{~min}$ at $4^{\circ} \mathrm{C}$ with gentle agitation, after which the lysate was sonicated for $10 \mathrm{~min}$. Lysate was cleared from the cell debris by centrifugation at 13,000 rpm for $20 \mathrm{~min}$. Protein concentration in the lysate was determined using the BCA protein assay kit (Pierce) with BSA as a standard.

Ten picomoles of biotinylated RNA was heated for $10 \mathrm{~min}$ to $60^{\circ} \mathrm{C}$ and slow-cooled over the course of $40 \mathrm{~min}$ to $4^{\circ} \mathrm{C}$. RNA was mixed with $1 \mathrm{mg}$ of precleared embryonic stem cell lysate in RIP buffer supplemented with tRNA $(0.1 \mu \mathrm{g} / \mu \mathrm{L}), 5 \mathrm{mM} \mathrm{MgCl}$, and $80 \mathrm{U} / \mathrm{mL}$ RNaseOut (Invitrogen) and incubated for $2 \mathrm{~h}$ at $4^{\circ} \mathrm{C}$ with gentle rotation. Twenty-five microliters of washed $\mathrm{T} 1$ Streptavidin magnetic Dynabeads (Invitrogen) was added to each binding reaction and further incubated for $2 \mathrm{~h}$ at $4^{\circ} \mathrm{C}$. Beads were washed three times with RIP-supplemented buffer (each wash carried out for $5 \mathrm{~min}$ at $4^{\circ} \mathrm{C}$ ) and then boiled in SDS buffer loading buffer. The retrieved proteins were separated by a $4 \%-12 \%$ gradient Bis-Tris SDS-polyacrylamide gel (Invitrogen) in MOPS buffer. The proteins on the gel were visualized using a SYPRO Ruby stain (Invitrogen). The sample was digested with trypsin and analyzed with nanoLC/ MS/MS at the University of Pennsylvania Proteomics Core. The data were analyzed with Sequest and Scaffold software packages.

Cell lysate from $10^{7}$ embryonic stem cells transfected with the plasmid MR225874 (Origene) expressing C-terminal MycDDK-tagged Purb under the control of the CMV promoter was prepared as described above using $1 \mathrm{~mL}$ of RIP buffer supplement with $80 \mathrm{U} / \mathrm{mL}$ RNaseOut. Antibodies targeting the Myc epitope (Cell Signaling, no. 2278P) or targeting IgG (Cell Signaling, no. 2729S) were added to $0.4 \mathrm{mg}$ of the cell lysate and incubated for $2 \mathrm{~h}$ at $4{ }^{\circ} \mathrm{C}$ with gentle rotation. Twenty-five microliters of protein $\mathrm{G}$ magnetic Dynabeads (Invitrogen) was added to the mix and incubated for $1 \mathrm{~h}$ at $4^{\circ} \mathrm{C}$ with gentle rotation. Beads were collected and washed three times with
$800 \mathrm{~mL}$ of RIP buffer supplemented with RNaseOut, with each wash being carried out for $5 \mathrm{~min}$ at $4^{\circ} \mathrm{C}$. Beads were resuspended in $700 \mu \mathrm{L}$ of Qiazol, and RNA was extracted from the beads using the miRNeasy minikit (Qiagen) and treated with RNase-free DNase I (Qiagen) according to the manufacturer's instructions. RNA from $50 \mu \mathrm{L}$ of the total lysate was extracted simultaneously and used as positive control for RNA extraction, reverse transcription, and the PCR reaction. We generated cDNA from the RNA using both poly-dT oligonucleotide and E5 rev as primers for the reverse transcription reaction. The presence of the noncoding RNA lincHOXA1 in the cDNA samples was detected using PCR using the primers lncHoxa1E3bFor and lncHoxa1E3cRev (Supplemental Table 2).

\section{Acknowledgments}

We thank Biosearch Technologies for providing many reagents crucial to these experiments. We also thank Gautham Nair for help with statistical analysis, Marshall Levesque for help with image analysis, and Ezgi Hacisuleyman for help with the RNA pull-down experiments. We thank other members of the Raj laboratory for useful discussions. H.M. and A.R. acknowledge support from a Burroughs-Wellcome Fund Career Award at the Scientific Interface. A.R. also acknowledges support from an NIH Director's New Innovator Award (1DP2OD008514). M.N.C. is supported by a Howard Hughes Medical Institute International Student Research Fellowship. J.R. acknowledges support from Director's New Innovator Awards 1DP2OD00667, P01GM099117, and P50HG006193-01. J.R. is a Damon RunyonRachleff, Searle, Smith Family, and Merkin Fellow.

\section{References}

Bergemann AD, Johnson EM. 1992. The HeLa Pur factor binds single-stranded DNA at a specific element conserved in gene flanking regions and origins of DNA replication. Mol Cell Biol 12: 1257-1265.

Cabili MN, Trapnell C, Goff L, Koziol M, Tazon-Vega B, Regev A, Rinn JL. 2011. Integrative annotation of human large intergenic noncoding RNAs reveals global properties and specific subclasses. Genes Dev 25: 1915-1927.

Carninci P, Kasukawa T, Katayama S, Gough J, Frith MC, Maeda N, Oyama R, Ravasi T, Lenhard B, Wells C, et al. 2005. The transcriptional landscape of the mammalian genome. Science 309: 1559-1563.

Choi PJ, Cai L, Frieda K, Xie XS. 2008. A stochastic singlemolecule event triggers phenotype switching of a bacterial cell. Science 322: 442-446.

Chubb JR, Trcek T, Shenoy SM, Singer RH. 2006. Transcriptional pulsing of a developmental gene. Curr Biol 16: 10181025.

Derrien T, Johnson R, Bussotti G, Tanzer A, Djebali S, Tilgner H, Guernec G, Martin D, Merkel A, Knowles DG, et al. 2012. The GENCODE v7 catalog of human long noncoding RNAs: Analysis of their gene structure, evolution, and expression. Genome Res 22: 1775-1789.

Dinger ME, Amaral PP, Mercer TR, Pang KC, Bruce SJ, Gardiner BB, Askarian-Amiri ME, Ru K, Soldà G, Simons C, et al. 2008. Long noncoding RNAs in mouse embryonic stem cell pluripotency and differentiation. Genome Res 18: 1433-1445.

Dupé V, Davenne M, Brocard J, Dollé P, Mark M, Dierich A, Chambon P, Rijli FM. 1997. In vivo functional analysis of the Hoxa-1 3' retinoic acid response element (3'RARE). Development 124: 399-410. 
The ENCODE Project Consortium, Birney E, Stamatoyannopoulos JA, Dutta A, Guigó R, Gingeras TR, Margulies EH, Weng Z, Snyder M, Dermitzakis ET, et al. 2007. Identification and analysis of functional elements in $1 \%$ of the human genome by the ENCODE pilot project. Nature 447: 799-816.

Fremeau RT, Lundblad JR, Pritchett DB, Wilcox JN, Roberts JL. 1986. Regulation of pro-opiomelanocortin gene transcription in individual cell nuclei. Science 234: 1265-1269.

Gallia GL, Darbinian N, Johnson EM, Khalili K. 1999. Selfassociation of Pur $\alpha$ is mediated by RNA. J Cell Biochem 74: 334-348.

Golding I, Paulsson J, Zawilski SM, Cox EC. 2005. Real-time kinetics of gene activity in individual bacteria. Cell 123: $1025-1036$.

Guttman M, Garber M, Levin JZ, Donaghey J, Robinson J, Adiconis X, Fan L, Koziol MJ, Gnirke A, Nusbaum C, et al. 2010. Ab initio reconstruction of cell type-specific transcriptomes in mouse reveals the conserved multi-exonic structure of lincRNAs. Nat Biotechnol 28: 503-510.

Guttman M, Donaghey J, Carey BW, Garber M, Grenier JK, Munson G, Young G, Lucas AB, Ach R, Bruhn L, et al. 2011. lincRNAs act in the circuitry controlling pluripotency and differentiation. Nature 477: 295-300.

Hawkins PG, Morris KV. 2010. Transcriptional regulation of Oct4 by a long non-coding RNA antisense to Oct4-pseudogene 5. transcription 1: 165-175.

Hu W, Alvarez-Dominguez JR, Lodish HF. 2012. Regulation of mammalian cell differentiation by long non-coding RNAs. EMBO Rep 13: 971-983.

Huarte M, Guttman M, Feldser D, Garber M, Koziol MJ, Kenzelmann-Broz D, Khalil AM, Zuk O, Amit I, Rabani M, et al. 2010. A large intergenic noncoding RNA induced by p53 mediates global gene repression in the p53 response. Cell 142: 409-419.

Ingolia NT, Lareau LF, Weissman JS. 2011. Ribosome profiling of mouse embryonic stem cells reveals the complexity and dynamics of mammalian proteomes. Cell 147: 789-802.

Kapranov P, Drenkow J, Cheng J, Long J, Helt G, Dike S, Gingeras TR. 2005. Examples of the complex architecture of the human transcriptome revealed by RACE and highdensity tiling arrays. Genome Res 15: 987-997.

Lai F, Orom UA, Cesaroni M, Beringer M, Taatjes DJ, Blobel GA, Shiekhattar R. 2013. Activating RNAs associate with Mediator to enhance chromatin architecture and transcription. Nature 494: 497-501.

Lee JT. 2012. Epigenetic regulation by long noncoding RNAs. Science 338: 1435-1439.

Levesque MJ, Raj A. 2013. Single-chromosome transcriptional profiling reveals chromosomal gene expression regulation. Nat Methods 10: 246-248.

Liang X-H, Vickers TA, Guo S, Crooke ST. 2011. Efficient and specific knockdown of small non-coding RNAs in mammalian cells and in mice. Nucleic Acids Res 39: e13.

Lin MF, Jungreis I, Kellis M. 2011. PhyloCSF: A comparative genomics method to distinguish protein coding and noncoding regions. Bioinformatics 27: i275-i282.

Maamar H, Raj A, Dubnau D. 2007. Noise in gene expression determines cell fate in Bacillus subtilis. Science 317: 526-529.

Mainguy G, Koster J, Woltering J, Jansen H, Durston A. 2007. Extensive polycistronism and antisense transcription in the Mammalian Hox clusters. PLOS ONE 2: e356.

Mercer T, Dinger M, Mattick J. 2009. Long non-coding RNAs: Insights into functions. Nat Rev Genet 10: 155-159.

Ørom UA, Shiekhattar R. 2011. Noncoding RNAs and enhancers: Complications of a long-distance relationship. Trends Genet 27: 433-439.
Ørom UA, Derrien T, Beringer M, Gumireddy K, Gardini A, Bussotti G, Lai F, Zytnicki M, Notredame C, Huang Q, et al. 2010. Long noncoding RNAs with enhancer-like function in human cells. Cell 143: 46-58.

Pauli A, Rinn JL, Schier AF. 2011. Non-coding RNAs as regulators of embryogenesis. Nat Rev Genet 12: 136-149.

Petruk S, Sedkov Y, Riley KM, Hodgson J, Schweisguth F, Hirose S, Jaynes JB, Brock HW, Mazo A. 2006. Transcription of bxd noncoding RNAs promoted by trithorax represses Ubx in cis by transcriptional interference. Cell 127: 1209-1221.

Ponting CP, Oliver PL, Reik W. 2009. Evolution and functions of long noncoding RNAs. Cell 136: 629-641.

Pruitt KD, Tatusova T, Maglott DR. 2003. NCBI Reference Sequence project: Update and current status. Nucleic Acids Res 31: 34-37.

Raj A, Tyagi S. 2010. Detection of individual endogenous RNA transcripts in situ using multiple singly labeled probes. Methods Enzymol 472: 365-386.

Raj A, Peskin CS, Tranchina D, Vargas DY, Tyagi S. 2006. Stochastic mRNA synthesis in mammalian cells. PLoS Biol 4: e309.

Raj A, van den Bogaard P, Rifkin SA, van Oudenaarden A, Tyagi S. 2008. Imaging individual mRNA molecules using multiple singly labeled probes. Nat Methods 5: 877-879.

Raj A, Rifkin SA, Andersen EC, van Oudenaarden A. 2010. Variability in gene expression underlies incomplete penetrance. Nature 463: 913-918.

Ramsey JE, Kelm RJ Jr. 2009. Mechanism of strand-specific smooth muscle $\alpha$-actin enhancer interaction by purine-rich element binding protein B (Purß). J Phys Chem B 48: 6348-6360.

Rinn JL, Chang HY. 2012. Genome regulation by long noncoding RNAs. Annu Rev Biochem 81: 145-166.

Rinn JL, Kertesz M, Wang JK, Squazzo SL, Xu X, Brugmann SA, Goodnough LH, Helms JA, Farnham PJ, Segal E, et al. 2007. Functional demarcation of active and silent chromatin domains in human HOX loci by noncoding RNAs. Cell 129: 1311-1323.

Suter DM, Molina N, Gatfield D, Schneider K, Schibler U, Naef F. 2011. Mammalian genes are transcribed with widely different bursting kinetics. Science 332: 472-474.

Tan-Wong SM, Zaugg JB, Camblong J, Xu Z, Zhang DW, Mischo HE, Ansari AZ, Luscombe NM, Steinmetz LM, Proudfoot NJ. 2012. Gene loops enhance transcriptional directionality. Science 338: 671-675.

Vargas DY, Raj A, Marras SAE, Kramer FR, Tyagi S. 2005. Mechanism of mRNA transport in the nucleus. Proc Natl Acad Sci 102: 17008-17013.

Wang KC, Yang YW, Liu B, Sanyal A, Corces-Zimmerman R, Chen Y, Lajoie BR, Protacio A, Flynn RA, Gupta RA, et al. 2011. A long noncoding RNA maintains active chromatin to coordinate homeotic gene expression. Nature 472: 120-124.

Xing Y, Johnson CV, Dobner PR, Lawrence JB. 1993. Higher level organization of individual gene transcription and RNA splicing. Science 259: 1326-1330.

Zhang X, Lian Z, Padden C, Gerstein MB, Rozowsky J, Snyder M, Gingeras TR, Kapranov P, Weissman SM, Newburger PE. 2009. A myelopoiesis-associated regulatory intergenic noncoding RNA transcript within the human HOXA cluster. Blood 113: 2526-2534. 


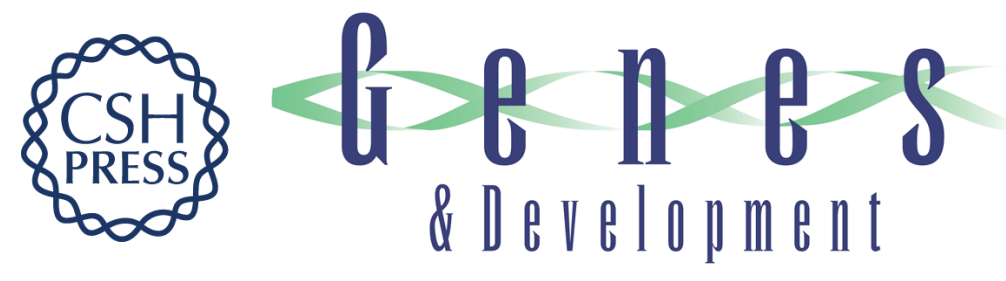

\section{linc-HOXA1 is a noncoding RNA that represses Hoxa1 transcription in cis}

Hédia Maamar, Moran N. Cabili, John Rinn, et al.

Genes Dev. 2013, 27: originally published online May 30, 2013

Access the most recent version at doi:10.1101/gad.217018.113

\section{Supplemental http://genesdev.cshlp.org/content/suppl/2013/05/29/gad.217018.113.DC1 Material}

References This article cites 46 articles, 16 of which can be accessed free at: http://genesdev.cshlp.org/content/27/11/1260.full.html\#ref-list-1

\section{License}

Email Alerting

Receive free email alerts when new articles cite this article - sign up in the box at the top Service 